\title{
Between authoritarian and dialogical approaches: attitudes and opinions on coercion among professionals in mental health and addiction care in Norway
}

\author{
Olaf Gjerløw Aasland \\ Institute for Study of the Medical Profession \\ Oslo \\ and \\ Center for Medical Ethics Department \\ of Health and Society University of \\ Oslo \\ Tonje Lossius Husum \\ Reidun Førde \\ Reidar Pedersen \\ Center for Medical Ethics Department \\ of Health and Society University of \\ Oslo \\ Norway
}

Corresponding author:

Olaf GjerløwAasland

Institute for Studies of the Medical Profession

P.O.B. 1152 Sentrum N-

0107 Oslo

Noway

+4790667320

olaf2306@gmail.com 


\begin{abstract}
More knowledge is needed on how to reduce the prevalence of formal and informal coercion in Norwegian mental health care. To explore possible reasons for the widespread differences in coercive practice in psychiatry and drug addiction treatment in Norway, and the poor compliance to change initiatives, we performed a nationwide survey. Six vignettes from concrete and realistic clinical situations where coercive measures were among the alternative courses of action, and where the difference between authoritarian (paternalistic) and dialogical (user participation) practices was explicitly delineated, were presented in an electronic questionnaire distributed to five groups of professionals: psychiatrists, psychologists, nurses, other professionals and auxiliary treatment staff . Non-coercive dialogical resolutions were more likely than coercive authoritative. However, there is a clear professional hierarchy with regard to authoritarian approaches, with the psychiatrists on top, followed by nurses and other professionals, and with psychologists as the least authoritarian. The majority of the respondents sometimes prefer actions that are illegal, which suggests that individual opinions about coercion often overrule legislation. The variation between and within professional groups in attitudes and opinions on coercion is extensive, and may account for some of the hitherto meagre results of two ministerial action plans for coercion reduction.
\end{abstract}




\section{Introduction}

The use of coercion in mental health and addiction care raises difficult ethical questions, and the views are moving towards more user participation, patients' rights, and human rights. There is growing evidence on the negative effects of paternalistic attitudes and practice (Kallert, 2008; Steinert, Noorthoorn, \& Mulder, 2014; R. Wynn, 2006), and an increasing trend away from patient needs and towards increased security (Sashidharan et Saraceno, 2017). Over the last ten years the Norwegian health authorities have launched two action plans to reduce the use of coercion and improve quality in mental health and addiction care, but with relatively little effect (Directorate of Health, 2006; Ministry of Health, 2012). Other European countries have also deliberately tried to reduce the use of coercion in care (Steinert et al., 2014). Legislation varies widely between countries, and practice varies, also within countries (Husum, Hem, \& Pedersen, 2017 (In press)). Furthermore, Norway with its population of about 5 million inhabitants is one of only few countries with two modes of involuntary admission in psychiatry: one for observation and one for treatment. This makes international comparison difficult. In 2015 there were 3873 approved cases of coercive observation and 3951 approved cases of coercive treatment, with a considerable geographic variation (Pedersen et al., 2016).

The aim of this study is to describe how different professions who work in mental health and substance abuse settings perceive the necessity for use of different coercive measures. Based on six vignettes from concrete and realistic clinical situations where coercive measures are among the alternative courses of action, and where the difference between authoritarian (paternalistic) and dialogical (user participation) approaches is explored, it is the first Norwegian national survey on normative attitudes and opinions and inclinations to use coercive approaches in this field. It is also part of a comprehensive research program on Mental health care, ethics and coercion, based at The Centre for Medical Ethics, Institute of 
Health and Society, Faculty of Medicine, University of Oslo (Center for Medical Ethics, 2017).

\section{Method}

The Norwegian health care system is organized through four regional and 26 local specialist health care authorities plus 426 municipalities with responsibility for primary health care. We performed an anonymous electronic survey among professionals and treatment staff from all parts of the Norwegian psychiatric and addiction treatment system including hospital-based wards, outpatient clinics (DPS) and municipal services. Ideally we wanted to communicate directly to all potential respondents with the possibility to allocate them to their respective workplaces, but The Norwegian Centre for Research Data (NSD, 2017) advised against identifying the workplaces geographically on a lower level than one of the four regional health authorities. For optimal dissemination of the electronic questionnaires we contacted the five most relevant professional organisations or unions, who through their respective communication systems invited and encouraged members who worked in mental health and addiction care to participate. These were The Norwegian Medical Association (psychiatrists or doctors training in psychiatry, "psychiatrists" in this article), The Norwegian Psychological Association (psychologists working in mental health and substance abuse treatment settings, "psychologists" in this article), The Norwegian Nurses Organization (nurses working in mental health and substance abuse treatment settings, "nurses" in this article), The Norwegian Union of Social Educators and Social Workers (social workers, child welfare officers and social educators working in mental health and substance abuse treatment settings, "other professionals" in this article), and The Norwegian Union of Municipal and General Employees (auxiliary nurses and others working in mental health and substance abuse treatment settings, "others" in this article). 
Each organisation sent e-mails with a link to the electronic questionnaire to those members who according to their membership registers worked in relevant mental health settings, a total of 15576 professionals (table 1 ).

Since all answers where anonymous, it was not possible to send individual reminders, but the respondents seem fairly representative, with the necessary power for our analyses. The questionnaire link was open between June 16 and December 172014.

Table 1 in here (Distributing organisations, recipients and respondents)

\subsection{Variables}

\subsubsection{Vignettes}

The survey was built around six vignettes with clinical dilemmas, suggesting from two to five more or less authoritative/coercive action alternatives (see frame below). All respondents completed all six vignettes. The vignettes were based on descriptions of ethically challenging situations taken from focus group interviews with staff (Hem, Molewijk, \& Pedersen, 2014), suggestions from a reference group that also included user representatives, and the researchers' previous knowledge and experience. On two vignettes (D and E) some of the suggested action alternatives were illegal, but this was not signaled in the questionnaire. The questionnaires were in Norwegian. For the purpose of this article, the vignettes with their action alternatives, as well as the relevant questions and answers, were translated and back-translated between Norwegian and English. The complete questionnaire (in Norwegian) can be obtained from the authors upon request. The six vignettes are depicted in Box 1:"The vignettes with their action alternatives are depicted in Box 1: 


\section{Box 1 The six vignettes with action alternatives}

\section{Vignette A (Patient will not wash)}

A patient with paranoid delusions refuses to wash and groom his/her hair, and smells so badly that fellow patients, relatives and staff are offended. In your opinion, what should be done?

1. Keep trying and persuade the patient to wash and freshen up ${ }^{0}$

2. Shower and wash the patient against his/her will ${ }^{1}$

3. Something else, what? (describe briefly)

\section{Vignette B (Patient posts pictures and videos)}

Despite many warnings, a patient who is admitted in accordance with compulsory mental health care legislation takes compromising pictures and video clips of him-/herself and post them on a blog accessible to everyone. The patient's reason to do this is that he/she thereby feels less isolated from the outside world. In your opinion, what should be done?

1. Continue with warnings, but otherwise do nothing more ${ }^{0}$

2. Confiscate the phone and make sure the patient does not have a phone

3. Something else, what? (Describe briefly)

\section{Vignette C (Well-functioning patient with schizophrenia refuses to take medication)}

A patient with diagnosed schizophrenia is assigned to compulsory psychiatric outpatient treatment. He refuses to take his prescribed medicine because it makes him stiff and dull. He is functioning well and has not recently experienced any psychotic symptoms, but has past experiences with relapse after a few weeks when not using medication. In your opinion, what should be done?

1. Leave it to the patient to decide ${ }^{0}$

2. Await the situation and see the patient regularly while trying to persuade him to continue with medication $^{0}$

3. Suggest a controlled and slow reduction in medication ${ }^{0}$

4. Administer a depot injection against the patient's will after a formal decision of coerced ${ }^{1}$ treatment

5. Something else, what? (Describe briefly)

\section{Vignette D (Suicidal patient)}

A patient is perceived as suicidal by his GP as well as by his family, but has no serious mental disorder and does not want help from the health service. In your opinion, what should be done?

1. Leave it to the patient to decide ${ }^{0}$

2. Await the situation and see the patient regularly while trying to persuade him to seek help ${ }^{0}$

3. Admit the patient to coerced observation ${ }^{1 *}$

4. Establish formal compulsory psychiatric treatment ${ }^{1 *}$

5. Admit the patient according to emergency law regulations ${ }^{1 *}$

6. Something else, what? (Describe briefly)

\section{Vignette E (Patient without capacity to consent)}

A patient is seriously mentally ill without capacity to consent. General function is deteriorating with increasing psychotic symptoms, despite good follow-up from the outpatient clinic and municipally services, and the conclusion is that inpatient treatment may stabilize and perhaps improve the condition. The patient is not against admittance, neither verbally nor physically. In your opinion, what should be done?

1. Admit the patient voluntarily ${ }^{0 *}$

2. Admit the patient to coerced observation ${ }^{1}$

3. Establish formal compulsory psychiatric treatment ${ }^{1}$

4. Something else, what? (Describe briefly)

\section{Vignette F (Illegal drugs in the institution)}

A voluntarily admitted active drug user is smuggling drugs into the institution and sells to fellow patients. In your opinion, what should be done?

1. Start an intensive effort for the patient to quit drugs and not sell of drug in the institution, eventually by threatening with discharge ${ }^{0}$

2. Discharge with or without follow up ${ }^{1}$

3. Something else, what? (describe as briefly as possible)

${ }^{0}$ dialogical, ${ }^{1}$ authoritative, $*$ illegal 


\subsubsection{Demographic and control variables}

In addition to profession (psychiatrist/MD, psychologist, nurse, other profession, other) the following categorical variables were included: sex, age-group (20-29, 30-39, 40-49, $50-59,60+)$, years of experience $(<2$ years, 2-5 years, 5-10 years, 10-15 years, $>15$ years), regional health authority (RH South-East, RH West, RH Central Norway, RH North), treatment setting (psychiatry, addiction treatment), and whether the respondent was formally responsible for local coercion decisions (pertains to psychiatrists and psychology specialists only).

\subsection{Statistical procedures}

After having assessed the frequencies of the different action alternatives, including the verbatim suggestions, the alternatives were dichotomized into dialogical (usually with some degree of user participation) and authoritative (usually paternalistic), and the six binary variables were used as responses in six multivariable logistic models. We also calculated a global authoritative score by summing across all six vignettes, ranging from 0 (no authoritative actions on any of the six vignettes) to 6 (authoritative actions on all six vignettes). The distribution of this variable was close to normal, with mean 2.16 and SD 1.185 .

Frequency tables, logistic regression models and error bar graphs are used for group comparisons, mainly between professions where statistically significant differences are shown either with p-values from chi-squared tests in contingency tables or with odds ratios with not overlapping $95 \%$ confidence intervals (fractions and means) or not including 1.0 (logistic regression models). SPSS version 24 was used for all analyses.

\subsection{Ethical approval}


The survey was approved by The Norwegian Centre for Research Data (NSD, 2017).

\section{Results}

\subsection{Response pattern on the six vignettes}

We received altogether 1160 responses, an over-all response rate of $7.5 \%$ (1160/15576), varying from $5 \%$ of the nurses to $12 \%$ of the psychiatrists and the members of The Norwegian Union of Social Educators and Social Workers. As shown in table 1 the mix of professionals is fairly representative of the national distribution. There was a modest overrepresentation of psychiatrists and social workers and a modest underrepresentation of the other professional groups.

The frequencies of the different suggested action alternatives across the five professional groups are summarized in table 2.

Table 2 in here (Frequencies of the different suggested action alternatives across the five professional groups)

\subsubsection{Summary of the differences in action alternatives}

Vignette A (Patient will not wash). The majority of the respondents (between $66 \%$ and 76 $\%$ ) would "keep trying". $16.7 \%$ of the psychiatrists would shower and wash against the patients will, which is more than any other professional group, and statistically significant more than e.g. $7.4 \%$ among "other professions" $(p=0.001)$.

Vignette B (Patient posts videos and pictures). $67 \%$ of the respondents, $87 \%$ of the psychiatrist would confiscate the phone, as opposed to e.g. $62.7 \%$ of the psychologists $(\mathrm{p}<0.001)$. 
Vignette C (Well-functioning patient with schizophrenia refuses to take medication). About half in all professional groups suggest alternative 2, to "Await the situation and see the patient regularly while trying to persuade him to continue with medication". $17.6 \%$ of the psychiatrists and $8.3 \%$ of the psychologists suggest a depot injection against the patient's will $(\mathrm{p}=0.003)$.

Vignette D (Suicidal patient). $47.8 \%$ of the psychiatrists and $48.6 \%$ of the psychologists will await the situation and see the patient regularly, as opposed to e.g.

$32.5 \%$ of the nurses, who preferred more authoritative alternatives (admit to coerced observation or according to emergency law regulations). ( $\mathrm{p}<0.001$ for nurses vs. psychiatrists and psychologists)

Vignette E (Patient without capacity to consent)

Almost $75 \%$ of all respondents would admit the patient voluntarily, which is not allowed (see below). $26 \%$ of the psychiatrists and $16 \%$ of the psychologists would establish formal compulsory treatment.

Vignette F (Illegal drugs in institution)

More than half of the respondents would "Start an intensive effort for the patient to quit and not sell drugs in the institution", whereas only between $11 \%$ and $17 \%$ would discharge the patient, with or without follow-up. Between $22.7 \%$ (other professions) and $37.2 \%$ (psychiatrists) suggested other action alternatives.

\subsubsection{Illegal actions}

In total there were four illegal options included in Vignettes D and E. One of the three illegal options of Vignette D - Admit the patient to coerced observation, Establish formal compulsory psychiatric treatment or Admit the patient according to emergency law regulations - were chosen by $52.4 \%$ of the respondents. The illegal option of vignette $\mathrm{E}$ Admit the patient without capacity to consent voluntarily - was chosen by 74.9 
$\%$ of the respondents. Here nurses chose illegal options statistically significant more frequently than e.g. psychiatrists: $79.3(73.5-84.3)$ vs. $65.7(58.8-72.1)$.

\subsection{Dichotomizing the different action alternatives into "dialogical" and}

\section{"authoritative"}

The action alternatives, including the written suggestions under "something else", were dichotomized into dialogical (usually not coercing) and authoritative (usually coercing). For each vignette a multivariate logistic regression model was applied, with authoritative vs. dialogical as the response variable, and gender, profession, experience and regional health authority as predictors. Age and psychiatric vs. addiction treatment unit had no statistically significant effects in any of the six models, and are not included (Table 3).

Table 3 in here (Effects of gender, profession, experience and regional health authority on scoring "authoritative" on each of the six vignettes)

\subsubsection{Summary of statistically significant effects}

Vignette A (Patient will not wash): In this study psychologists are less likely than psychiatrists to act authoritatively.

Vignette B (Patient posts videos and pictures): In this study males more than females, and all the other professions are less likely than the psychiatrists to act authoritatively. Vignette $\mathrm{C}$ (Well-functioning patient with schizophrenia refuses to take medicine): In this study males are more likely than females and psychiatrists are more likely than psychologists to act authoritatively. The most experienced are more authoritative, as is the Central Norwegian health authority compared with the South East.

Vignette D (Suicidal patient): In this study nurses and others are more likely to act 
authoritatively than psychiatrists, as are the West and North health authorities compared to the South East.

Vignette E (Incapacitated patient): In this study nurses and other professions are less likely than psychiatrists to act authoritatively.

Vignette F (Illegal drugs in the institution): In this study psychiatrists are more likely to act authoritatively than most other professions. Longer experience also gives more authoritative actions.

\subsection{Global authoritative summary score}

The Global authoritative score is the sum of the responses across the six vignettes. There are statistically significant differences between professions, see Figure 1.

mean 2.16

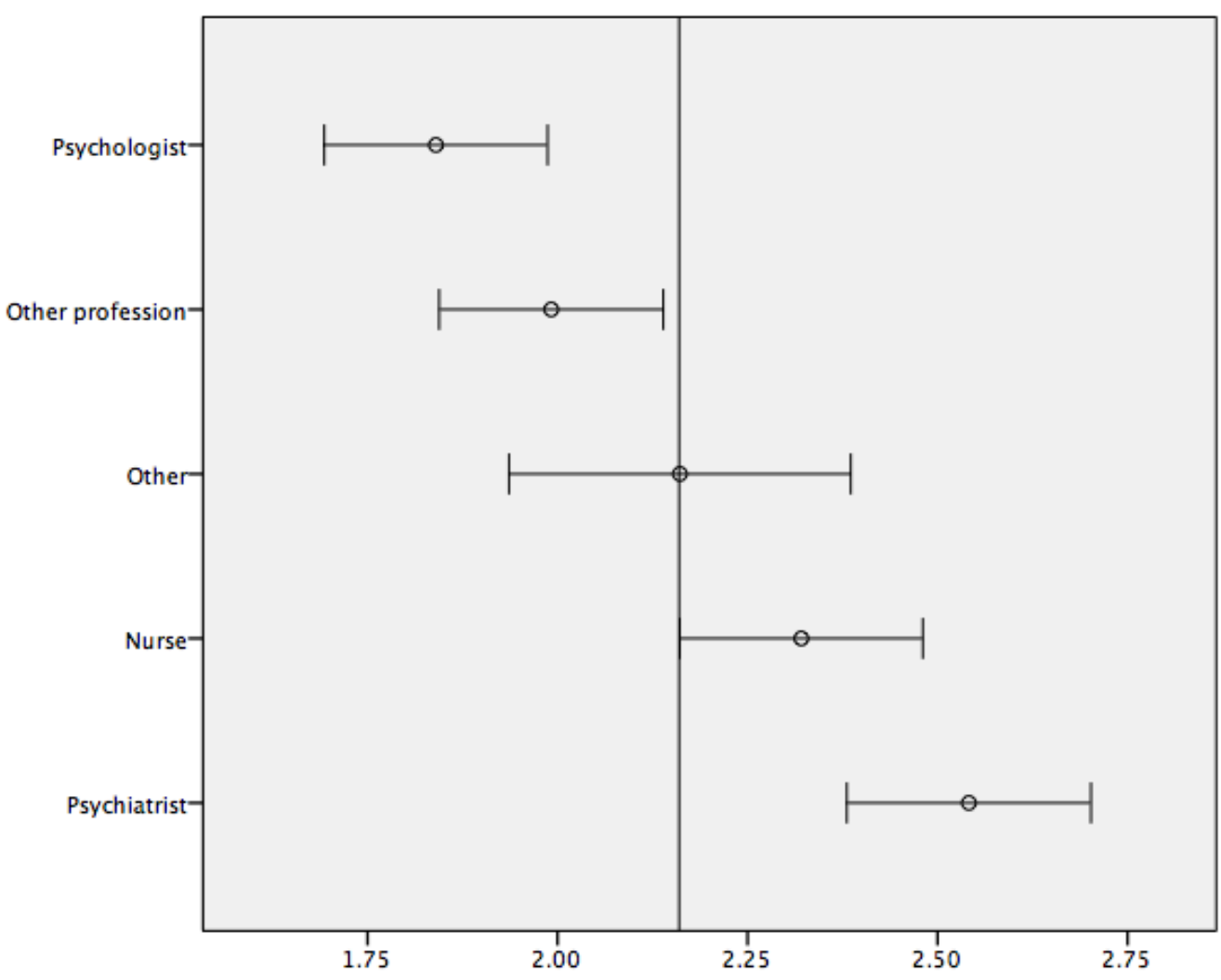


Figure 1 Means with 95\% confidence intervals of the Global authoritative score for the five professional groups.

Psychiatrists and nurses score statistically significant higher than psychologists and other professions (95\% confidence intervals not overlapping).

\section{Discussion}

The present study is addressing ethical challenges related to coercion, which is increasingly a topic in demand (Hem, Gjerberg, Husum, \& Pedersen, 2016). There are also some indications that coercive interventions are not always in compliance with legislation (Feiring \& Ugstad, 2014; Molewijk, 2016), which we attempt to elucidate. In addition, morally problematic behavior and power abuse may accompany the use of coercive measures, e.g. using coercion as a punishment, or coercive actions not covered by law. Our vignettes also touch upon this, at least indirectly.

\subsection{Use of vignettes}

The use of vignettes is a well-recognized method to standardize data on attitudes, opinions and potential interventions in different groups of health personnel (Hughes \& Huby, 2002; Kristiansen et al., 2001; Peabody et al., 2004). In this study we used examples about coercion from staff focus group interviews, supplemented with input from stakeholder organisations and representatives, to create the vignettes and the action alternatives. For vignettes $\mathrm{A}$ to $\mathrm{E}$ the proposed action alternatives seemed relevant, as relatively few ( $2 \%$ to $17 \%$ ) of the respondents suggested other actions. On vignette F $30 \%$ suggested other actions, which indicates that we did not quite succeed in describing relevant options. However, in the subsequent process of identifying coercive and authoritative actions all suggestions were included, not only the pre-coded ones. 


\subsection{Strengths}

This study is the first nation-wide standardized (vignette-based) coercion study including all categories of staff in all workplaces in psychiatry and drug addiction treatment in Norway. Its main strength lies in the detailed and relevant action alternatives. Hopefully it can be used as a reference for future similar studies.

\subsection{Weaknesses}

A major motive for our research was to increase the knowledge about why there are so stable and extensive geographical variations in the use of coercion in Norwegian mental health care (Nyttingnes \& Husum, 2011). But since we could not allocate the respondents to their actual workplace, not to speak of identifying important local opinion leaders, we are left with assessing the differences between professional groups. There is reason to believe that necessary changes in attitudes and practice with regard to coercion may be hindered by experienced doctors or nurses who do not believe in radical changes of practice (Steinert et al., 2014).

Another shortcoming is of course the low response rate. Had we been able to communicate directly with all potential respondents through individual reminders the response rate would have been better. Based on information from the five different professional organizations we know approximately how many potential respondents there were, and how they are distributed across the different professions (Table 1). This is slightly better than in the study by Wynn et al. that was also based on vignettes in an anonymous questionnaire published on a web-site, but with a completely unknown number of potential respondents.

\subsection{The difference between psychologists and psychiatrists}


There is a considerable variety in the respondents' choices among the different suggested actions, but more often towards non-coercive or dialogical interventions than not. However, the most striking finding is the almost systematic polarity between psychologists and psychiatrists, which has probably not been shown so explicitly before. Psychologists are less authoritative and more dialogical, while psychiatrists are more willing to apply coercion. The other professions usually place themselves between the psychologists and the psychiatrists, with the nurses next to the psychiatrists.

An actual difference between psychiatrists and psychologists is of course the fact that in the ordinary clinical setting only psychiatrists prescribe medication, and according to Lund (Lund, 2017), 94\% of all protocolled decisions about coercive treatment in Norway are about medication. However, the difference goes far beyond this particular clinical setting, all the way back to the very origins of these two professions. The younger science of psychology originally evolved from studies on general human perceptions and behavior, while psychiatry has always been preoccupied with deviance and pathology. But psychologists gradually also focused on abnormal behavior and psychotherapy. Historically psychiatry is rife with dramatic, authoritative and often failed attempts to help patients with mental disorders through heroic surgical, physical or pharmacological interventions (Cappelen-Damm, 2004; Gullestad, 2014). Despite this fundamental difference in origin, the ordinary citizen is usually not able to distinguish between psychiatrists and psychologists. This ignorance is also reflected in the legislation where the two professions are often equated, for instance with regard to being formally responsible for the use of coercion in a clinical setting (except coercive use of medication). In Norway each treatment unit must have a formal decision-maker when coercive interventions are to be implemented, and the decision-maker can be either a psychiatrist or a clinical psychologist (Justice, 1999). 
Among our respondents $51.7 \%$ (109/211) of the psychiatrists and $22.9 \%(59 / 258)$ of the psychologists were formal decision-makers, but being a decision-maker did not have any statistically significant influence on choice of interventions. On the global authoritative score decision-making psychologists scored slightly but not statistically significant higher than their non decision-making colleagues: $2.09(1,82-2,36)$ vs 1.76 , $(1.58-1,93)$, but statistically significant lower than decision-making psychiatrists $(2.65$ $(2.42-2.87))$.

Our findings on the polarity between psychiatrists and psychologists are in line with what Wynn et al. (R. Wynn, Myklebust, \& Bratlid, 2007) found in their study on attitudes to coercion among 683 health-care workers in Norway. Doctors were more willing to coerce that psychologists, both with regard to coerced treatment (means of 69.8 for psychologists and 73.0 for doctors, with a group mean for all occupations of 72.9), and with regard to coerced admission (means of 43.6 and 55.4 respectively, with group mean for all occupations of 48.1). Strangely, the authors did not discuss this particular finding.

Our data suggest that the profession of the decision-maker may make a difference, but unfortunately they do not allow for comparing psychologist-decisions and psychiatristdecisions. Feiring \& Ugstad (Feiring \& Ugstad, 2014) show in their qualitative study of 10 experienced clinicians (psychiatrist/psychologist) how ". . . a deliberative-oriented ideal of reasoning about legal criteria for involuntary admissions lapses into paternalism in clinical decision-making", which suggests that culture and tradition may be more important than professional ideal-types. Nevertheless, to what extent the fact that both psychologists and psychiatrists with their different subcultures and traditions are decision-makers with regard to coercive interventions may contribute to local variations in coercive practices should 
definitely be researched further.

\subsection{Illegal interventions}

The public interest around the use of coercion in Norwegian mental health care is increasing, including potential illegal use (Lund, 2017; NRK, 2015; TV2, 2010) An interesting and perhaps worrisome finding in the present study is that the majority of respondents in some situations suggest illegal actions. We do not know whether these answers reflect ignorance of the law or disagreement with the current regulation. The fact that a considerable fraction of the respondents suggest illegal actions strongly indicates a need for more knowledge about legal regulation among health care professionals and/or more open discussions about the legitimacy of current coercive regulation. The answers may also reflect that the legal regulation is unclear or too complicated. Law closely regulates mental health care, and our findings call for increased awareness of law and ethics in the education of health care professionals, as well as in their daily work.

\subsection{Differences between regional health authorities}

The South East health authority is statistically significant more authoritative on vignette $\mathrm{C}$, and less on vignette $\mathrm{D}$. However, due to the large variation within each authority, we do not consider this an important finding.

\section{Conclusion}

In a variety of ethical dilemmas in Norwegian mental health care, when the question of possible use of formal or informal coercion is raised, a non-coercive dialogical resolution is more likely than a coercive or authoritative one. However, there is a clear professional hierarchy with regard to authoritarian approaches, with the psychiatrists on top, followed by nurses and other professionals, and with psychologists most often 
preferring dialogical approaches. The majority of the professionals sometimes prefer actions that are illegal, which suggests that individual opinions about coercion often overrule the legislation, which again may explain the hitherto meagre results of two ministerial action plans for coercion reduction. 


\section{References}

Cappelen-Damm. (2004). Psykologiens historie og utvikling Retrieved from http://psykologi.cappelendamm.no/binfil/download.php?did=68672

Center for Medical Ethica, U. o. O. (2017). Mental health care, ethics and coercion. Retrieved from http://www.med.uio.no/helsam/english/research/projects/mental-health-careethics-and-coercion/index.html

Directorate of Health. (2006). Action plan for quality insured and reduced use of coercion in mental health care 2006-2011. Retrieved from Oslo:

https://www.regjeringen.no/globalassets/upload/x_ryddekatalog/tiltaksplan_for_red u_10902a-liten.pdf

Feiring, E., \& Ugstad, K. N. (2014). Interpretations of legal criteria for involuntary psychiatric admission: a qualitative analysis. BMC Health Serv Res, 14, 500. doi:10.1186/s 12913-014-0500-x

Gullestad, S. E. (2014). Psykologi - et samfunnsvitenskapelig fag? . In R. Kalleberg (Ed.), Kritisk samfunnsvitenskap - den gang og nå. (pp. 89-96). Oslo. Retrieved from http://www.sv.uio.no/iss/om/aktuelt/2014/bok-kritisk-samfunnsvitenskap-.html

Hem, M. H., Gjerberg, E., Husum, T. L., \& Pedersen, R. (2016). Ethical challenges when using coercion in mental healthcare: A systematic literature review. Nurs Ethics. doi:10.1177/0969733016629770

Hem, M. H., Molewijk, B., \& Pedersen, R. (2014). Ethical challenges in connection with the use of coercion: a focus group study of health care personnel in mental health care. BMC Med Ethics, 15, 82. doi:10.1186/1472-6939-15-82

Hughes, R., \& Huby, M. (2002). The application of vignettes in social and nursing research. $J$ Adv Nurs, 37(4), 382-386.

Husum, T., Hem, M., \& Pedersen, R. (2017 (In press)). A survey of mental healthcare staff's perception of ethical challenges related to the use of coercion in care. In J. H. J. N. Gather, A; Vollmann, J; (Ed.), Beneficial coercion in psychiatry? Foundations and challenges. Münster: Mentis Verlag.

Justice, M. o. (1999). Lovdata §3.2, English translation. Oslo. Retrieved from http://app.uio.no/ub/ujur/oversatte-lover/data/lov-19990702-062-eng.pdf.

Kallert, T. W. (2008). Coercion in psychiatry. Curr Opin Psychiatry, 21(5), 485-489. doi:10.1097/YCO.0b013e328305e49f

Kristiansen, I. S., Forde, O. H., Aasland, O., Hotvedt, R., Johnsen, R., \& Forde, R. (2001). Threats from patients and their effects on medical decision making: a crosssectional, randomised trial. Lancet, 357(9264), 1258-1261. doi:10.1016/S01406736(00)04407-X

Lund, K. (2017). Tvangsmedisinering må forbys. Tidsskr Nor Legeforen, 137, 3.

Ministry of Health. (2012). Action plan for quality insured and reduced use of coercion in mental health care 2012-2015. Retrieved from Oslo: https://www.regjeringen.no/globalassets/upload/HOD/Bedrekvalitetokt_frivillighet.pdf

Molewijk, A. E., IS, Pedersn, R. . (2016). Two years of moral case deliberations on the use of coercion in mental health care: Which ethical challenges are being discussed by health care professionals? Clinical Ethics, 11, 9.

NRK. (2015). Pasienter utsatt for ulovlig bruk av tvang (Patients subjected to unlawful use of coercion). Retrieved from https://www.nrk.no/rogaland/pasienter-utsatt-forulovlig- bruk-av-tvang-1.12450488

NSD. (2017). Retrieved from http://www.nsd.uib.no/nsd/english/index.html 
Nyttingnes, O., \& Husum, T. (2011). Omfang, utvikling og geografisk variasjon i bruk av tvang i psykisk helsevern i Norge (Volume, development and geographical variation in use of coercion in mental health care in Norway). Impuls, 64, 12.

Peabody, J. W., Luck, J., Glassman, P., Jain, S., Hansen, J., Spell, M., \& Lee, M. (2004).

Measuring the quality of physician practice by using clinical vignettes: a prospective validation study. Ann Intern Med, 141(10), 771-780.

Pedersen, P. B., Hellevik, V., Skui, H. (2016) Kontroll av tvangsbruk i psykisk helsevern i 2015. (Control of use of coercion in mental health.) Norwegian Directorate of Health.

https://helsedirektoratet.no/Lists/Publikasjoner/Attachments/1251/Kontroll_av_tvan g_2015_IS-2452-2015.pdf

Sashidharan, S. P., Saraceno, B. (2017). Is psychiatry becoming more coercive? BMJ, 357: j2904

Steinert, T., Noorthoorn, E. O., \& Mulder, C. L. (2014). The use of coercive interventions in mental health care in Germany and the Netherlands. A comparison of the developments in two neighboring countries. Front Public Health, 2, 141. doi:10.3389/fpubh.2014.00141

TV2. (2010). Ukjente konsevenser av tvangsbruk i psykiatrien (Unknown consequences of coercion). Retrieved from http://www.tv2.no/a/3135199

Wynn, R. (2006). Coercion in psychiatric care: clinical, legal, and ethical controversies. Int J Psychiatry Clin Pract, 10(4), 247-251. doi:10.1080/13651500600650026

Wynn, R., Myklebust, L., \& Bratlid, T. (2007). Psychologists and coercion: decisions regarding involuntary psychiatric admission and treatment in a group of Norwegian psychologists. Nord J Psychaitry, 61(6), 4. doi:

10.1080/08039480701773139. 
Table 1 Distributing organisations, recipients and respondents

\begin{tabular}{|c|c|c|c|}
\hline Organisation/union & Professions & $\begin{array}{l}\text { Recipients ( } \mathrm{N}=\mathbf{1 5 5 7 6} \text { ) } \\
\text { Column percent }\end{array}$ & $\begin{array}{l}\text { Respondents ( } \mathbf{N}=\mathbf{1 1 6 0} \text { ) } \\
\text { Column percent with } 95 \% \mathrm{Cl} \\
\text { Row percent (response) }\end{array}$ \\
\hline $\begin{array}{l}\text { The Norwegian Medical } \\
\text { Association }\end{array}$ & $\begin{array}{l}\text { Psychiatrists and } \\
\text { psychiatrists in } \\
\text { training }\end{array}$ & $\begin{array}{r}1812 \\
(12 \%)\end{array}$ & $\begin{array}{r}211 \\
(18(16-20) \%) \\
11.6 \% \\
\end{array}$ \\
\hline $\begin{array}{l}\text { The Norwegian } \\
\text { Psychological Association }\end{array}$ & $\begin{array}{l}\text { Selected licenced } \\
\text { Psychologist }\end{array}$ & $\begin{array}{r}3928 \\
(25 \%)\end{array}$ & $\begin{array}{r}258 \\
(22(20-24) \%) \\
6,6 \%\end{array}$ \\
\hline $\begin{array}{l}\text { Norwegian Nurses } \\
\text { Organisation }\end{array}$ & $\begin{array}{l}\text { Nurses working in } \\
\text { psychiatric and } \\
\text { addiction treatment } \\
\text { settings }\end{array}$ & $\begin{array}{r}4659 \\
(30 \%)\end{array}$ & $\begin{array}{r}233 \\
(20(18-22) \%) \\
5,0 \%\end{array}$ \\
\hline $\begin{array}{l}\text { Norwegian Union of Social } \\
\text { Educators and Social } \\
\text { Workers }\end{array}$ & $\begin{array}{l}\text { Social workers } \\
\text { Child welfare officers } \\
\text { Social educators }\end{array}$ & $\begin{array}{r}2313 \\
(15 \%)\end{array}$ & $\begin{array}{r}286 \\
(25(23-28) \%) \\
12,4 \%\end{array}$ \\
\hline $\begin{array}{l}\text { Norwegian Union of } \\
\text { Municipal and General } \\
\text { Employees }\end{array}$ & $\begin{array}{l}\text { Auxiliary nurses and } \\
\text { others }\end{array}$ & $\begin{array}{r}2864 \\
(18 \%)\end{array}$ & $\begin{array}{r}172 \\
(15(13-17) \%) \\
6,0 \%\end{array}$ \\
\hline All & & $\begin{array}{r}15576 \\
(100 \%)\end{array}$ & $\begin{array}{r}1160 \\
(100 \%) \\
7.5 \% \\
\end{array}$ \\
\hline
\end{tabular}




\begin{tabular}{|c|c|c|c|c|c|c|c|c|c|c|c|c|}
\hline \multirow[b]{2}{*}{ A Patient will not wash } & \multicolumn{2}{|c|}{ Psychiatrist } & \multicolumn{2}{|c|}{ Psychologist } & \multicolumn{2}{|l|}{ Nurse } & \multicolumn{2}{|c|}{ Other profession } & \multicolumn{2}{|l|}{ Other } & \multicolumn{2}{|l|}{ Total } \\
\hline & $\mathrm{N}$ & $\%$ & $\mathrm{~N}$ & $\%$ & $\mathrm{~N}$ & $\%$ & $\mathrm{~N}$ & $\%$ & $\mathrm{~N}$ & $\%$ & $\mathrm{~N}$ & $\%$ \\
\hline 1 Keep trying and persuade the patient to wash and freshen up & 147 & $70.3 \%$ & 190 & $75.1 \%$ & 154 & $66.1 \%$ & 219 & $76.8 \%$ & 102 & $69.9 \%$ & 812 & $72.1 \%$ \\
\hline 2 Shower and wash the patient against his/her will & 35 & $16.7 \%$ & 23 & $9.1 \%$ & 26 & $11.2 \%$ & 21 & $7.4 \%$ & 17 & $11.6 \%$ & 122 & $10.8 \%$ \\
\hline 3 Something else & 27 & $12.9 \%$ & 40 & $15.8 \%$ & 53 & $22.7 \%$ & 45 & $15.8 \%$ & 27 & $18.5 \%$ & 192 & $17.1 \%$ \\
\hline Total & 209 & $99.9 \%$ & 253 & $100.0 \%$ & 233 & $100.0 \%$ & 285 & $100.0 \%$ & 146 & $100.0 \%$ & 1126 & $100.0 \%$ \\
\hline \multicolumn{13}{|l|}{ B Patient posts videos and pictures } \\
\hline 1 Continue with warnings, but otherwise do nothing more & 12 & $5.8 \%$ & 42 & $16.9 \%$ & 32 & $14.0 \%$ & 61 & $22.7 \%$ & 26 & $18.2 \%$ & 173 & $15.8 \%$ \\
\hline 2 Confiscate the phone and make sure the patient does not have a phone & 181 & $87.0 \%$ & 156 & $62.7 \%$ & 152 & $66.7 \%$ & 165 & $61.3 \%$ & 84 & $58.7 \%$ & 738 & $67.3 \%$ \\
\hline 3 Something else & 15 & $7.2 \%$ & 51 & $20.5 \%$ & 44 & $19.3 \%$ & 43 & $16.0 \%$ & 33 & $23.1 \%$ & 186 & $17.0 \%$ \\
\hline Total & 208 & $100.0 \%$ & 249 & $100.1 \%$ & 209 & $100.0 \%$ & 209 & $100.0 \%$ & 209 & $100.0 \%$ & 209 & $100.1 \%$ \\
\hline \multicolumn{13}{|l|}{ C Well-functioning patient with schizophrenia refuses to take medication } \\
\hline 1 Leave it to the patient to decide & 0 & $0.0 \%$ & 6 & $2.4 \%$ & 0 & $0.0 \%$ & 4 & $1.4 \%$ & 3 & $2.1 \%$ & 13 & $1.2 \%$ \\
\hline 2 Await the situation while trying to persuade him to continue with medication & 93 & $44.3 \%$ & 124 & $49.0 \%$ & 125 & $54.1 \%$ & 162 & $58.1 \%$ & 77 & $54.6 \%$ & 581 & $52.2 \%$ \\
\hline 3 Suggest a controlled and slow reduction in medication & 46 & $21.9 \%$ & 82 & $32.4 \%$ & 48 & $20.8 \%$ & 54 & $19.4 \%$ & 34 & $24.1 \%$ & 264 & $23.7 \%$ \\
\hline 4 Depot injection against the patient's will after a formal decision of coerced treatment & 37 & $17.6 \%$ & 21 & $8.3 \%$ & 38 & $16.5 \%$ & 44 & $15.8 \%$ & 16 & $11.3 \%$ & 156 & $14.0 \%$ \\
\hline 5 Something else & 34 & $16.2 \%$ & 20 & $7.9 \%$ & 20 & $8.7 \%$ & 15 & $5.4 \%$ & 11 & $7.8 \%$ & 100 & $9.0 \%$ \\
\hline Total & 210 & $100.0 \%$ & 253 & $100.0 \%$ & 231 & $100.1 \%$ & 279 & $100.1 \%$ & 141 & $99.9 \%$ & 1114 & $100.1 \%$ \\
\hline \multicolumn{13}{|l|}{ D: Suicidal patient } \\
\hline 1 Leave it to the patient to decide & 2 & $1.0 \%$ & 9 & $3.6 \%$ & 5 & $2.2 \%$ & 10 & $3.6 \%$ & 2 & $1.4 \%$ & 28 & $2.5 \%$ \\
\hline 2 See the patient regularly while trying to persuade him to seek help & 100 & $47.8 \%$ & 122 & $48.6 \%$ & 75 & $32.5 \%$ & 114 & $40.9 \%$ & 45 & $31.0 \%$ & 456 & $40.9 \%$ \\
\hline 3 Admit the patient to coerced observation & 81 & $38.8 \%$ & 66 & $26.3 \%$ & 82 & $35.5 \%$ & 84 & $30.1 \%$ & 47 & $32.4 \%$ & 360 & $32.3 \%$ \\
\hline 4 Establish formal compulsory psychiatric treatment & 2 & $1.0 \%$ & 3 & $1.2 \%$ & 5 & $2.2 \%$ & 14 & $5.0 \%$ & 8 & $5.5 \%$ & 32 & $2.9 \%$ \\
\hline 5 Admit the patient according to emergency law regulations & 10 & $4.8 \%$ & 33 & $13.1 \%$ & 48 & $20.8 \%$ & 46 & $16.5 \%$ & 31 & $21.4 \%$ & 168 & $15.1 \%$ \\
\hline 6 Something else & 14 & $6.7 \%$ & 18 & $7.2 \%$ & 16 & $6.9 \%$ & 11 & $3.9 \%$ & 12 & $8.3 \%$ & 71 & $6.4 \%$ \\
\hline Total & 209 & $100.1 \%$ & 251 & $100.0 \%$ & 231 & $100.1 \%$ & 279 & $100.0 \%$ & 145 & $100.0 \%$ & 1115 & $100.1 \%$ \\
\hline \multicolumn{13}{|l|}{ E Patient without capacity to consent } \\
\hline 1 Admit the patient voluntarily & 136 & $65.4 \%$ & 181 & $72.1 \%$ & 184 & $79.3 \%$ & 219 & $78.8 \%$ & 107 & $75.4 \%$ & 827 & $74.4 \%$ \\
\hline 2 Admit the patient to coerced observation & 13 & $6.3 \%$ & 22 & $8.8 \%$ & 31 & $13.4 \%$ & 34 & $12.2 \%$ & 20 & $14.1 \%$ & 120 & $10.8 \%$ \\
\hline 3 Establish formal compulsory psychiatric treatment & 54 & $26.0 \%$ & 41 & $16.3 \%$ & 13 & $5.6 \%$ & 18 & $6.5 \%$ & 12 & $8.5 \%$ & 138 & $12.4 \%$ \\
\hline 4 Something else & 5 & $2.4 \%$ & 7 & $2.8 \%$ & 4 & $1.7 \%$ & 7 & $2.5 \%$ & 3 & $2.1 \%$ & 26 & $2.3 \%$ \\
\hline Total & 208 & $100.1 \%$ & 251 & $100.0 \%$ & 232 & $100.0 \%$ & 278 & $100.0 \%$ & 142 & $100.1 \%$ & 1111 & $99.9 \%$ \\
\hline \multicolumn{13}{|l|}{ F lllegal drugs in the institution } \\
\hline 1 Urge the patient to quit and not sell drugs, eventually by threatening with discharge & 102 & $49.3 \%$ & 145 & $58.9 \%$ & 120 & $52.9 \%$ & 178 & $64.3 \%$ & 81 & $57.0 \%$ & 626 & $57.0 \%$ \\
\hline 2 Discharge but follow up the patient & 28 & $13.5 \%$ & 31 & $12.6 \%$ & 32 & $14.1 \%$ & 36 & $13.0 \%$ & 13 & $9.2 \%$ & 140 & $12.7 \%$ \\
\hline 3 Something else & 77 & $37.2 \%$ & 70 & $28.5 \%$ & 75 & $33.0 \%$ & 63 & $22.7 \%$ & 48 & $33.8 \%$ & 333 & $30.3 \%$ \\
\hline Total & 207 & $100.0 \%$ & 246 & $100.0 \%$ & 227 & $100.0 \%$ & 277 & $100.0 \%$ & 142 & $100.0 \%$ & 1099 & $100.0 \%$ \\
\hline
\end{tabular}


Table 3 Effects of gender, profession, experience and regional health authority on scoring "authoritive" on each of the six vignettes. Significant effects in bold

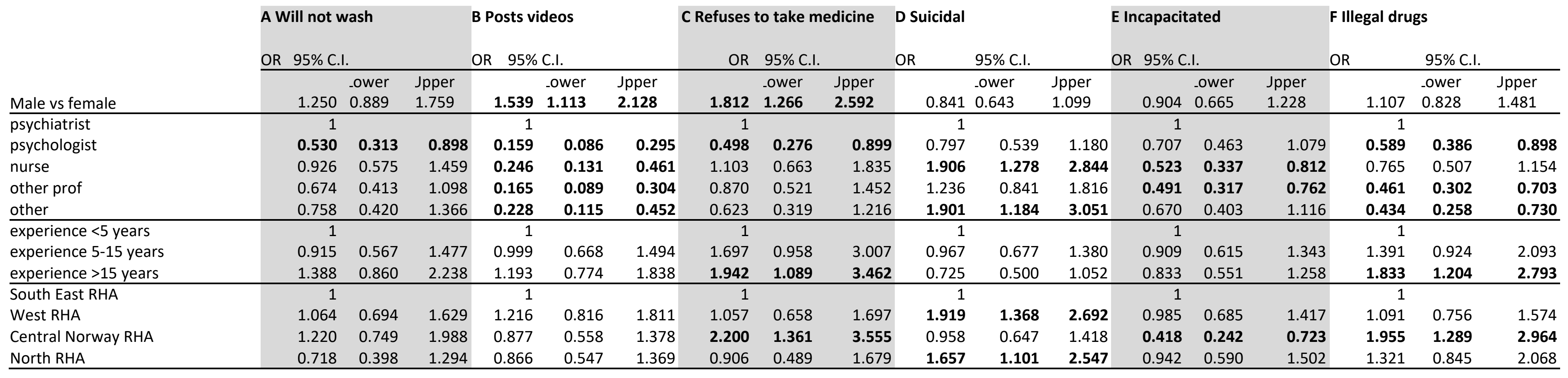

